\title{
Asymmetric Total Synthesis of (+)-Waihoensene
}<smiles>CCOC1=CC(=O)CCC1</smiles>

A

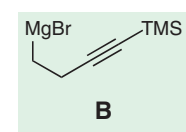<smiles>CC#CCCC1=CC(=O)CCC1</smiles>

C

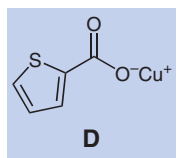

1. D $(5 \mathrm{~mol} \%)$, E (10 $\mathrm{mol} \%)$ $\mathrm{Me}_{3} \mathrm{Al}, \mathrm{Et}_{2} \mathrm{O},-30^{\circ} \mathrm{C}$ then $n-\mathrm{BuOCH}_{2} \mathrm{NEt}_{2}$ 2. $\mathrm{MCPBA}, \mathrm{CH}_{2} \mathrm{Cl}_{2}$

$61 \%, 91 \%$ ee

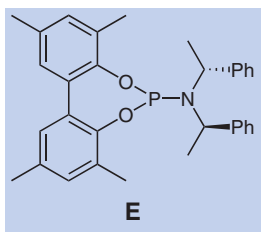<smiles>O=C1C=C2CCCC(CCCC2=O)C2(CCCC2)C1</smiles>

I
$\mathrm{Co}_{2}(\mathrm{CO})_{8}, \mathrm{~N}_{2} \mathrm{O}(1 \mathrm{~atm})$ DCE, $80^{\circ} \mathrm{C}$

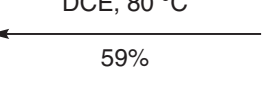

Pauson-Khand reaction

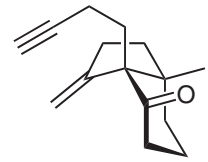

H

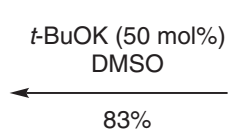

Conia-ene reaction
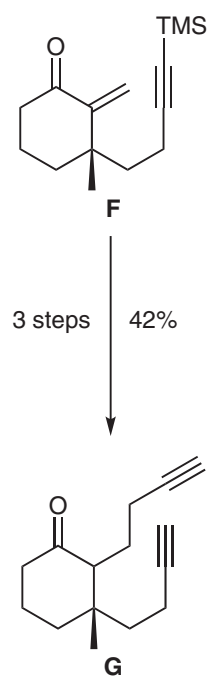

81\% $\mid \begin{gathered}\mathrm{Ni}(\mathrm{acac})_{2}(10 \mathrm{~mol} \%) \\ \mathrm{LiBr}, \mathrm{Me}_{2} \mathrm{Zn} \\ \mathrm{Et}_{2} \mathrm{O}-\mathrm{PhMe}(1.6: 1), 0^{\circ} \mathrm{C} \text { to r.t. }\end{gathered}$

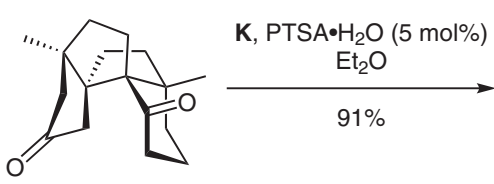

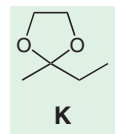

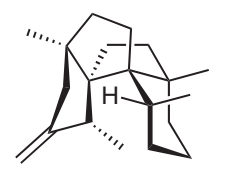

(+)-Waihoensene

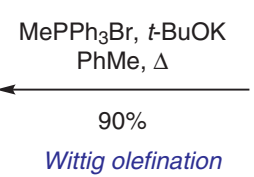

Wittig olefination

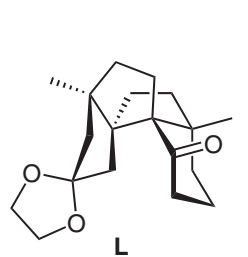

L

1. $\mathrm{MePPh}_{3} \mathrm{Br}, t$-BuOK

PhMe, $\Delta$

2. $1 \mathrm{M}$ aq $\mathrm{HCl}$

$\mathrm{THF}-\mathrm{H}_{2} \mathrm{O}(5: 1)$

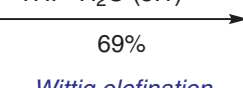

Wittig olefination

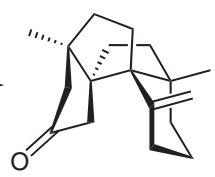

M

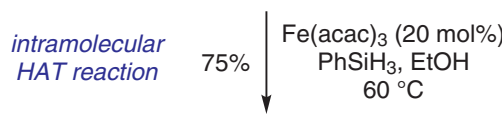
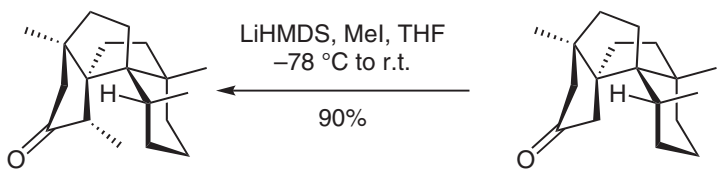

$\mathbf{N}$

Significance: Huang, Yang, and co-workers report the asymmetric synthesis of (+)-waihoensene in 15 steps. Waihoensene features a congested $[6,5,5,5]$ tetracyclic core, containing four contiguous quaternary carbons and a cis-fused six-membered ring.
Comment: In five steps, enone $\mathbf{A}$ is transformed into $\mathbf{G}$, which undergoes diastereoselective Coniaene reaction to $\mathbf{H}$. Enyne $\mathbf{H}$ is elaborated to $\mathbf{J}$ through a Pauson-Khand reaction, followed by a nickel-catalyzed 1,4-addition. Reduction of the exocyclic double bond is achieved by $\mathrm{Fe}(\mathrm{acac})_{3} / \mathrm{PhSiH}_{3}-$ mediated intramolecular HAT reaction to give $\mathbf{N}$. Shortly after the publication of this synthesis, Snyder and co-workers reported another synthesis of this natural product following a very similar strategy (Angew. Chem. Int. Ed. 2020, DOI: 10.1002/ anie.202004177).

\section{Key words}

(+)-waihoensene

Conia-ene reaction

Pauson-Khand reaction

Wittig olefination

intramolecular HAT reaction 